\title{
A combined approach for assessment the functionality of photovoltaic modules in real- world operation
}

\author{
Ivaylo Nedelchev $^{1 *}$ and Hristo Zhivomirov ${ }^{1}$ \\ ${ }^{1}$ Technical University of Varna, Department of Theory of Electrical Engineering and Measurements, \\ Bulgaria
}

\begin{abstract}
The energy production from the solar photovoltaic power plants is highly dependent on the meteorological and physical conditions such as solar radiation, ambient and panel's surface temperature, inclination of the photovoltaic (PV) panel construction etc. The I-V curves are the most important for estimation the functionality and production of each PV panel, as well as finding the maximum power point (MPP) of it. Because of the continuous generation of energy, the silicon crystal of the PV modules begins to depreciate and this decreases the energy production. In real-world operating conditions, revealing the energy state of the PV panels is the main point for estimating the PV panels' efficiency. Furthermore, one complete approach, including electrical measurements and temperature distribution information over the PV panels' surface, can reveal the risky elements (subcells) and provide data for prevention damages and working interruptions. This paper presents a method for PV monitoring in which conventional electrical instrumentation devises and thermographic camera are used, in order to estimate the real physical state of the PV panels'.
\end{abstract}

\section{Introduction}

The most of the PV power plants are all yearly exposed of the nature's influence such as wind, rain, snow and accumulation of dust. The depreciation of the PV panels is a crucial factor for energy production losses. The decreasing of the quality of the PV panel's crystal is direct consequence of this process. It is expressed in decreasing of the efficiency and fill factor (FF), existing of higher operating temperature of some panel's cells, expansion the resistive effects over the short circuit current $\left(\mathrm{I}_{\mathrm{SC}}\right)$ and open circuit voltage $\left(\mathrm{V}_{\mathrm{OC}}\right)$ etc. Fast assessment of all these effects and influence factors over the energy generation during dynamically changing operating conditions, allows quality maintenance of the large PV power plants and can be useful for prevention damages and energy losses [1-3].

The diagnostic and monitoring of the photovoltaic panels in working conditions requires many functional parameters to be known, as well as the meteorological data and the parameters of the location [1-3]. This paper represents a simple combined approach for PV panel monitoring involving measurements of the main electrical quantities of the PV panels

\footnotetext{
* Corresponding author: iynedelchev@abv.bg
} 
and thermographic measurements. The preliminary assessment about the location and solar radiation are also taken into account in the study.

\section{The observed physical parameters of the study}

\subsection{PV plant location parameters}

The main parameters of the PV plant location and specific parameters are shown in the Table $1[4]$.

Table 1. Parameters of the PV power plant's position, inverters and local time.

\begin{tabular}{|c|c|l|c|}
\hline Parameter & Value & \multicolumn{1}{|c|}{ Parameter } & Value \\
\hline Longitude, $\lambda$ & $41,47^{\circ}$ & Number of inverters & 15 \\
\hline Zenith angle, $\theta$ & $48,53^{\circ}$ & \multirow{2}{*}{ Model of the installed invertors } & $\begin{array}{c}\text { Woodward } \\
\text { IDS Solo 250 }\end{array}$ \\
\cline { 1 - 2 } Tilt angle, $\delta$ & $25^{\circ}$ & $\begin{array}{c}\text { Delta Solivia } \\
\text { EC G3 20 TL }\end{array}$ \\
\hline Day number of the year, D & 341 & Nominal AC power of the & $\begin{array}{c}250 \mathrm{~kW} \\
(10 \text { inverters })\end{array}$ \\
\cline { 1 - 2 } Altitude, $z$ & $217 \div 228 \mathrm{~m}$ & $\begin{array}{c}20 \mathrm{~kW} \\
(5 \text { inverters })\end{array}$ \\
\hline $\begin{array}{c}\text { Azimuth orientation (Direct } \\
\left.\text { North - } 0^{\circ}\right), \varphi A\end{array}$ & $180^{\circ}$ & Number of string boxes (SSB) & 35 \\
\hline Installed peak power, MW & 2,3 & Number of strings in each SSB & 13 or 14 \\
\hline $\begin{array}{l}\text { Number of power } \\
\text { substations }\end{array}$ & 5 & Total number of the strings & 407 \\
\hline $\begin{array}{l}\text { Nominal power of the } \\
\text { installed power substations }\end{array}$ & $500 \mathrm{kVA}$ & Number of panels in each string & 24 \\
\hline
\end{tabular}

Considering the short daytime of the season time period (in the beginning of December) and location (Southwest Bulgaria), the measurements was conducted during the day interval between 10 a.m. and 2 p.m.

\subsection{Parameters of the PV panel and measurement approach}

The objects of the measurement are PV panels, which location is chosen in random manner all over the PV power plant area. All tested modules belong to one kind of model. The operating period till the moment of the experiment is 5 years. Their electrical and physical parameters are given in the Table 2 [5]. The most important parameters of the tested PV panels are: peak power (measured by standard test conditions $-P_{m}$ ), peak efficiency $(\eta)$, short circuit current $\left(I_{s c}\right)$, open circuit voltage $\left(V_{O C}\right)$, maximum power current $\left(I_{m}\right)$, maximum power voltage $\left(V_{m}\right)$, effective surface area $(A)$, panel type, spectral sensitivity, system losses (according the panel's age, pollution, snow, shading, wiring, mismatch, connections, availability) etc. [1, 2, 3, 6, 7].

One of the functional parameters of each module is the surface temperature $(T)$. It is an important indicator for the resistive losses in each cell into the PV panel. The simultaneous measurement of the surface temperature can derives crucial information about the depreciation of the PV panel's elements. It is well known fact that the tilt of the construction is a precondition for unevenly collection of dust, snow or some other pollution on the panel's 
surface. Especially in snowy conditions the bottom side of the construction is still shaded, while the top side is illuminated. This fact can cause unequal aging of each panel's subcells and thus to decrease of the quality parameters of the entire module. It could be expected, that this process increases the intrinsic resistance of some cells of the bottom side of the module and therefore the operating temperature of the affected cells will rise slowly during the aging. Along with the conventional electrical measurements, there were included thermographic measurements, in order the temperature of the cells to be simultaneously detected and the temperature differences $(\Delta T)$ between them to be received. In this case, the temperature distribution along the vertical direction of the panel's construction will shows the maximum value of the $\Delta T$.

Table 2. Parameters of the tested modules.

\begin{tabular}{|c|c|c|c|}
\hline Parameter & Value & Parameter & Value \\
\hline STC power, $P$ & $235 \mathrm{~W}$ & effective surface area, $A$ & $1,5 \mathrm{~m}^{2}$ \\
\hline peak efficiency, $\eta$ & $14,5 \%$ & Array type & fixed \\
\hline short circuit current, $I_{S C}$ & $8,45 \mathrm{~A}$ & Panel type & a-Si \\
\hline open circuit voltage, $V O C$ & $37,3 \mathrm{~V}$ & System losses, $L S$ & $20 \%$ \\
\hline maximum power current, $I_{M}$ & $7,98 \mathrm{~A}$ & Number of cells, $\mathrm{N}$ & 60 \\
\hline maximum power voltage, $V_{M}$ & $29,5 \mathrm{~V}$ & effective surface area, $A$ & $1,5 \mathrm{~m}^{2}$ \\
\hline
\end{tabular}

The signal processing of the received thermographic images consists of the histogram and vertical thermal curve (VTC) of each image (each module respectively), as well as the biggest temperature difference $\left(\Delta T_{M}\right)$ on them. The thermographic signal processing was executed by the original software of the thermographic camera.

\section{Measurement approach and received results}

\subsection{Preliminary assessment and measurement of the solar radiation}

The executed monitoring of the panels consists of two stages: measurement of the physical quantities, which are used for estimation of the parameters of each tested PV panel and thermography. Firstly, $V_{O C}, I_{S C}$ and solar radiation of the tested panel are measured. On the second stage via thermography, the temperature distribution over the panel's surface was captured. Assessing the energy production requires the preliminary data for the solar radiation. For the purpose of the study some empirical approaches is used in order to find the level of the solar radiation at the location of measurements.

The global incident solar light reached an object laying on the Earth's surface consists of three main components: direct, diffused and reflected light. It was taken three approaches in order to assess the global solar radiation $I_{G}$ : empirical assessment [8 - 10], calculation from the global data bases [12 - 14] and direct measurement.

Empirically, the daily maximum of the solar radiation $I_{D}$ can be obtained by the formula $[9,10]:$

$$
I_{D}=1353 \cdot 0.7^{A M^{0.678}}
$$


The variable in the expression (1) is called air mass factor - $A M$. The parameter represents the path from the atmosphere that the light must pass through for reaching the Earth's surface, relative to the direct path through the zenith. The air mass factor can be found from $[8,9]$ :

$$
A M=\frac{1}{\cos (\theta)}
$$

where $\theta$ is the zenith angel: between the vertical of the position and the sun beam direction.

Considering other two components (diffused and reflected solar radiation), the global incident solar radiation on the Earth's surface object $I_{G}$ increases proportionally. Thus, the relation between them is $[2,3,14]$ :

$$
I_{G}=1,1 \cdot I_{D}
$$

Another source of information for assessing the incident global solar radiation $I_{G}$ is the global data bases [11 - 13], which represent the average value of $I_{G}$ for seasonal or daily time period. For calculating the incident global solar radiation, which effect on the tilted PV panel's surface, have to be used the expression:

$$
I_{G P V}=I_{G} \cdot \sin (\alpha+\delta)
$$

where $I_{G P V}$ is the global solar radiation which impacts on the PV panel, $\alpha$ is the elevation angle of the sun position, $\delta$ is the tilt angle of the PV construction across the Earth surface. According the number of the day $D$ in the year and latitude $\lambda$ of the measurement location, $\alpha$ is calculated to be $25,9^{\circ}$.

The real way to assess the solar radiation is direct measurement. The solar radiation was measured at the time period between $10 \mathrm{a} . \mathrm{m}$. and $2 \mathrm{p} . \mathrm{m}$. During the experiment in the real conditions, the moisture and clouds affected the measured data.

On the Table 3 are shown measurement data and the results of the both calculating approaches, reduced to PV panel's surface according (4). All the values are reduced to the tilted surface of the PV panel - $I_{G P V}$. The received data express daily maximum level of the $I_{G P V}$. For the further calculations measured value of $I_{G P V}$ were used.

Table 3. PV panel's data.

\begin{tabular}{|c|c|c|c|c|c|}
\hline \multicolumn{2}{|c|}{$\begin{array}{c}\text { Calculated via } \\
\text { Empirical approach }\end{array}$} & \multicolumn{2}{c|}{$\begin{array}{c}\text { Calculation via } \\
\text { Global data base (CMSAF) }\end{array}$} & \multicolumn{2}{c|}{ Measured } \\
\hline $\boldsymbol{I}_{\boldsymbol{G}}, \mathrm{W} / \mathrm{m}^{2}$ & $\boldsymbol{I}_{\boldsymbol{G P} \boldsymbol{V}, \mathrm{W} / \mathrm{m}^{2}}$ & $\boldsymbol{I}_{\boldsymbol{G}}, \mathrm{W} / \mathrm{m}^{2}$ & $\boldsymbol{I}_{\boldsymbol{G P} \boldsymbol{V}}, \mathrm{W} / \mathrm{m}^{2}$ & $\boldsymbol{I}_{\boldsymbol{G}}, \mathrm{W} / \mathrm{m}^{2}$ & $\boldsymbol{I}_{\boldsymbol{G} \boldsymbol{P} \boldsymbol{V}, \mathrm{W} / \mathrm{m}^{2}}$ \\
\hline 931,7 & 715,3 & 1020 & 783,7 & 655 & 503,6 \\
\hline
\end{tabular}

\subsection{Electrical measurements and efficiency calculations}

During the research, two electrical parameters were measured: short circuit current $I_{S C}$ and open circuit voltage $V_{O C}$ of more than hundred PV panels. In the Table 4 are shown the results of eight of them as a representative data of the whole electrical measurement. By use of the measured electrical values and catalogue data, can be obtained the next PV panel's parameters:

- Normalized $V_{O C}-v_{o c}$, which is calculated as [9]:

$$
v_{O C}=\frac{q}{m \cdot k_{B} \cdot T} \cdot V_{O C},
$$


In (5) $q=1,602 \cdot 10^{-19} \mathrm{C}$ is the elementary charge, $m$ is the ideality factor, $k_{B}=1,381 \cdot 10^{-23}$ $J / K$ is Boltzmann's constant and $T$ is absolute temperature. According to the model for the calculation of the identity factor $m$ and taking into account the measurement situation - direct solar radiation $\left(I_{D}\right)$ and ambient temperature $(T)$, the ideality factor was accepted to be $1,8[9$, 15].

- Fill factor $-F F$ - express the ratio between maximum output power and product of $V_{O C}, \mathrm{I}_{\mathrm{SC}}$. The next expression shows the empirical way for calculation the $F F$ by $v_{o c}[9,16,17]$ :

$$
F F=\frac{v_{o c}-l\left(v_{o c}+0,72\right)}{v_{o c}},
$$

- Maximum output power $-P_{M}$, obtained from the equation:

$$
P_{M}=F F \cdot V_{O C} \cdot I_{S C}
$$

- Efficiency - $\eta$. It depends on all parameters obtained above - measured electrical values and calculated $F F$ and $I_{G P V}[3,9]$. The expression for efficiency is:

$$
\eta=\frac{V_{o c} \cdot I_{S c} \cdot F F}{A \cdot I_{G P V}}
$$

In (8), $A$ is the parameter which shows the effective PV panel's working surface. For tested modules $A$ is received from catalog datasheet $\left(A=1,5 \mathrm{~m}^{2}\right)$ [5]. The calculated, as well as the measured data are shown on the Table 4 . The value of the ambient absolute temperature $T$ during the experiment is within the interval $280 \mathrm{~K} \div 285 \mathrm{~K}$.

Table 4. PV panel's data.

\begin{tabular}{|c|c|c|c|c|c|c|c|c|}
\hline № & 1 & 2 & 3 & 4 & 5 & 6 & 7 & 8 \\
\hline$V_{O C,} \mathrm{~V}$ & 34,9 & 35,3 & 35,2 & 35,5 & 35,3 & 35,1 & 36,2 & 35,7 \\
\hline$I_{S C,} \mathrm{~A}$ & 0,61 & 0,97 & 1,6 & 2,3 & 2,3 & 2,6 & 2,97 & 3,44 \\
\hline$I_{G P V}, \mathrm{~W} / \mathrm{m}^{2}$ & 92,9 & 135,1 & 251,8 & 336,6 & 343,9 & 402,9 & 464,3 & 503,6 \\
\hline$v_{o c}$ & 14,03 & 14,19 & 14,15 & 14,27 & 14,19 & 14,11 & 14,55 & 14,35 \\
\hline$F F$ & 0,754 & 0,756 & 0,756 & 0,757 & 0,756 & 0,755 & 0,760 & 0,758 \\
\hline$P_{M}, \mathrm{~W}$ & 16,1 & 25,9 & 42,6 & 61,8 & 61,4 & 68,9 & 81,8 & 93,1 \\
\hline$\eta, \%$ & 11,5 & 12,8 & 11,3 & 12,3 & 11,9 & 11,4 & 11,7 & 12,3 \\
\hline
\end{tabular}

\section{Thermography}

For the study there were captured more than hundred thermographic images of the PV modules. The images were received via thermal imager type TESTO 890 B. For measurements, from each formed string coupled in every string boxes (SSB) were chosen one panel. In that manner, the obtained results were collected from equally distanced areas, located all over the whole region of the PV plant. From the other hand, the measurement panels are chosen to belong to higher and lower rows of the existing metal construction. This type of distribution of the measurement objects was applied in order applicable statistical data to be obtained. By this type of string coupling, inverters distribution and specific area landscape (more than $11 \mathrm{~m}$. of denivelation of the terrain), it was tested only 1,5\% of the 
total number of the PV panels to be obtained the statistical relevant data for the entire PV plant.

On the Fig. $1 \div$ Fig. 8 , are represented the temperature distribution of the eight of them.

The shown patterns belong to distanced areas and strings and they are involved in a representative sample for the whole PV plant for further thermographic calculations and image processing. From the thermography it visible, that the temperature distribution shows higher temperature levels on the most of the bottom located cells of the PV panels. This phenomenon is connected with the tilt of the construction, which implies cumulating of the pollutions and longer time of shading during the snow season. The bottom area of some images shows more dissipated power and therefore losses, which is indicator for raised value of the intrinsic resistance of the more heated cells. This shows that the bottom cells probably have a different level of depreciation compared to the top located cells into the most of the PV panels. The bottom cells with the raised intrinsic resistance will reduce the output panel's current and thus the generated power and the PV panel's efficiency will be smaller.
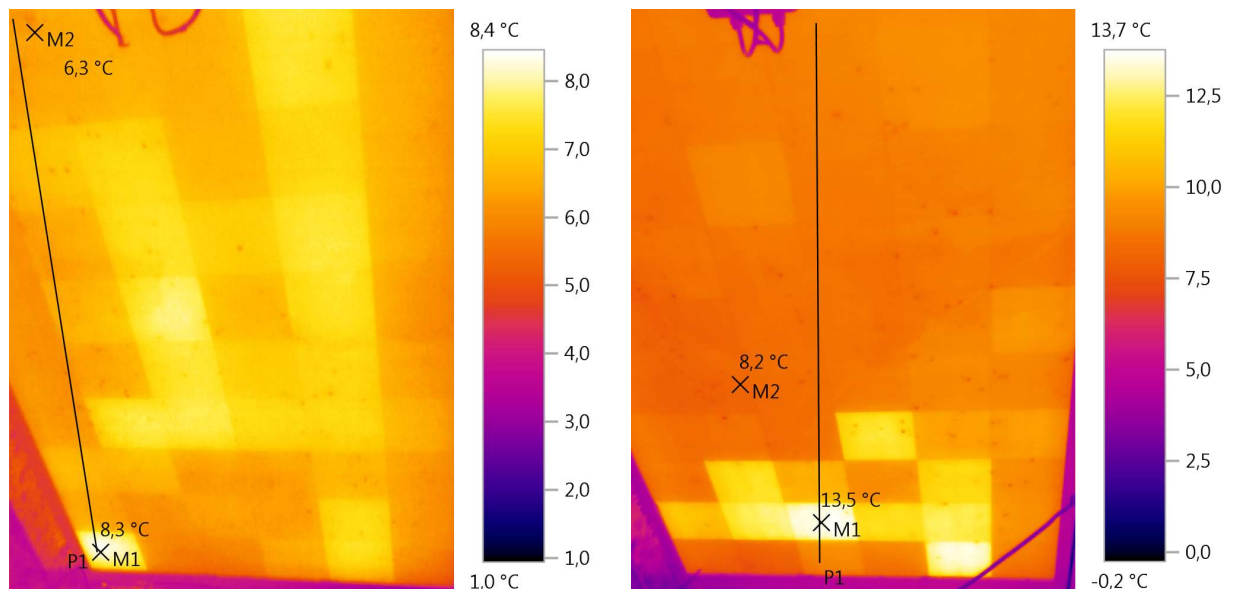

Fig. 1, Fig. 2. Temperature distribution of the tested PV panels № 1and № 2.
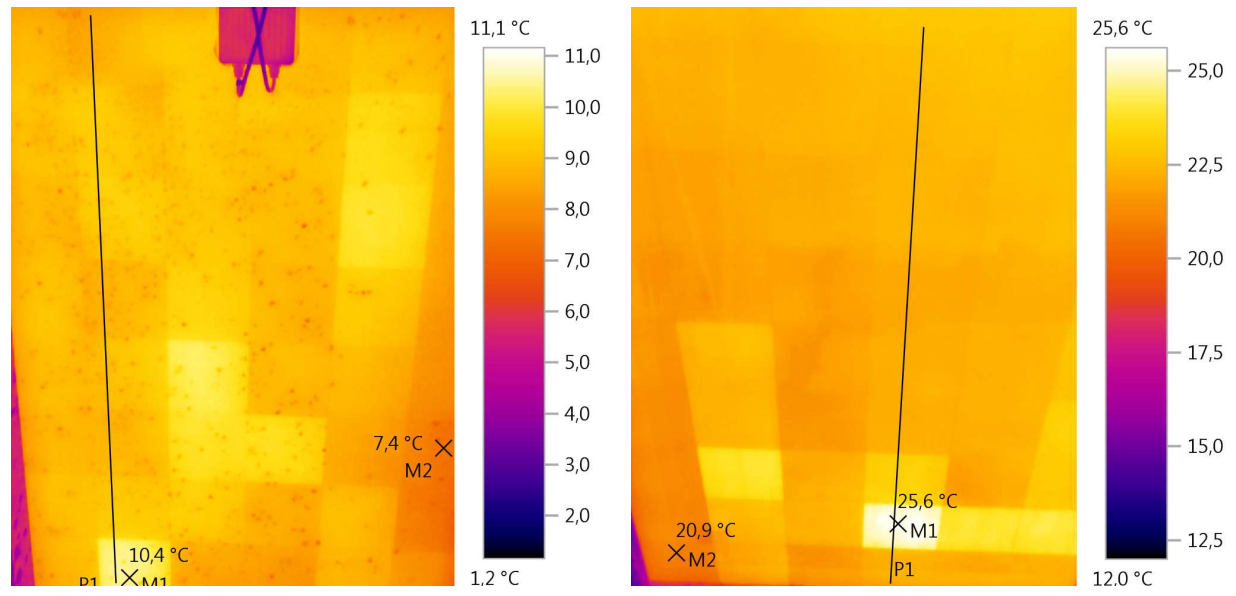

Fig. 3, Fig. 4. Temperature distribution of the tested PV panels № 3 and № 4. 

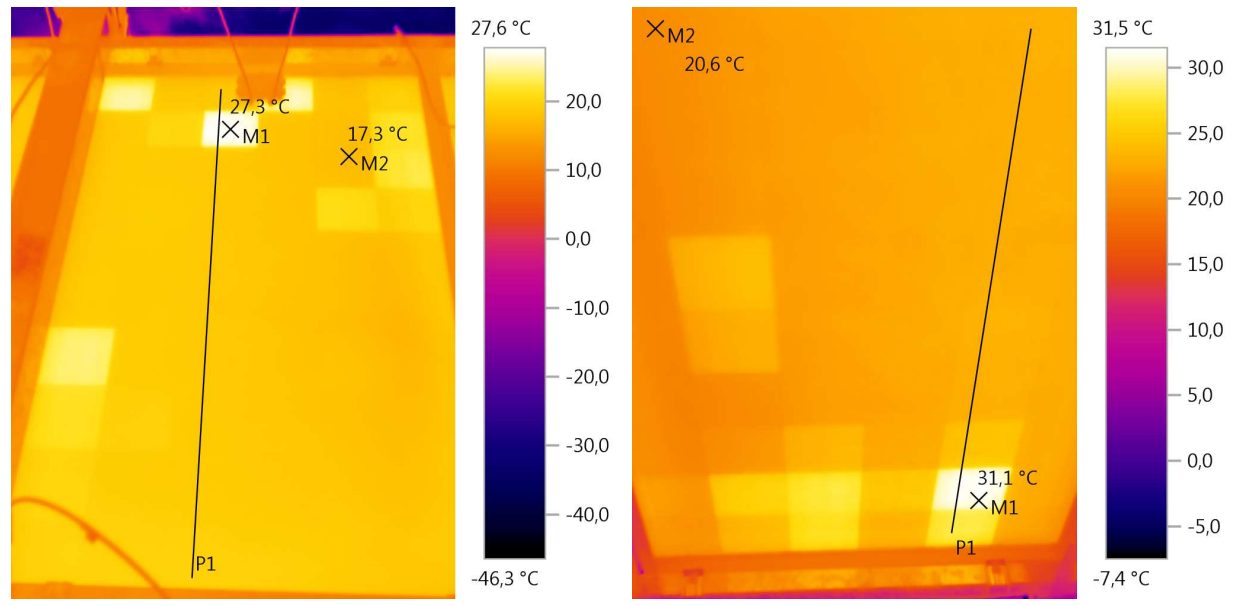

Fig. 5, Fig. 6. Temperature distribution of the tested PV panels № 5and № 6.
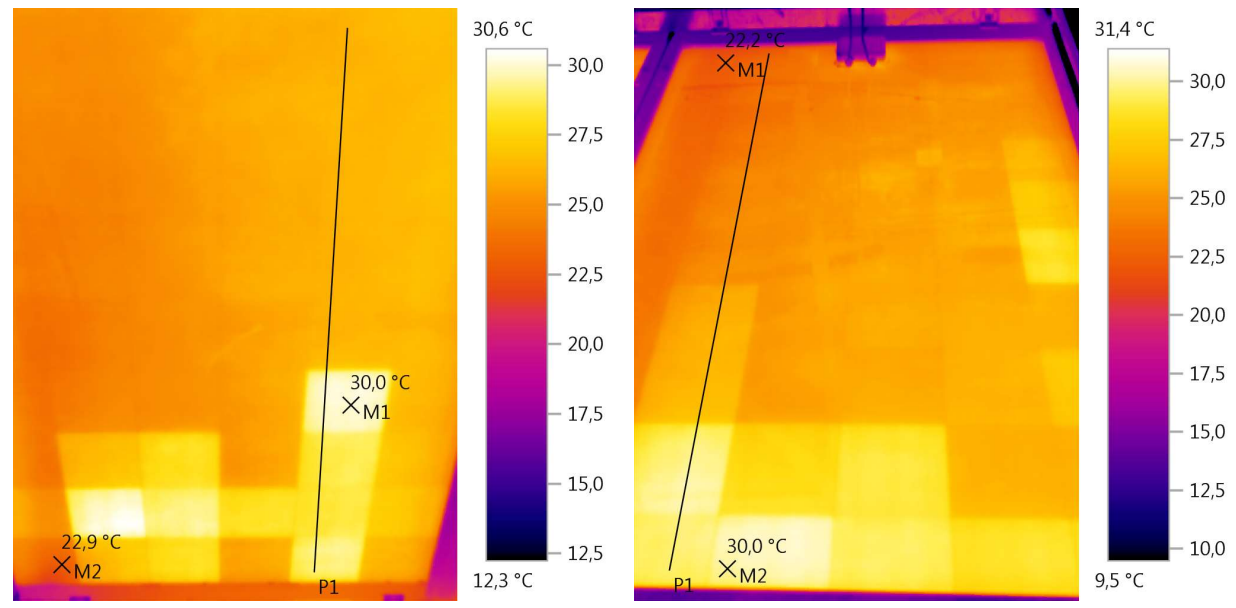

Fig. 7, Fig. 8. Temperature distribution of the tested PV panels № 7 and № 8.

\section{Results from processed thermographic images}

The processed data of the thermographic images include the histograms on two of the modules and their VTC's in direction from the top to the bottom. These charts are shown on the Fig. 9 - Fig. 12. The histograms (Fig. 9, Fig. 10) represent almost Laplace's distributions, with some exceptions and irregularities. These side components on the right of the maximum (on the higher temperature levels) express the overheated cells or these of them which are exposed of risk of damage. Vertical thermal curves of the tested PV panels № 2 and № 8 are shown on the Fig. 11, Fig.12. Calculated maximum temperature differences $\left(\Delta T_{M}\right)$ via thermography over the panel's surface are given in the Table 5.

Table 5. Maximum temperature differences on the surface of the tested PV panels.

\begin{tabular}{|c|c|c|c|c|c|c|c|c|}
\hline № & 1 & 2 & 3 & 4 & 5 & 6 & 7 & 8 \\
\hline$\Delta T_{M}{ }^{\circ}$ & 2 & 5,4 & 35,2 & 4,7 & 10,1 & 10,5 & 7,1 & 7,9 \\
\hline
\end{tabular}


They vary from $2{ }^{\circ} \mathrm{C}$ to $10,5^{\circ} \mathrm{C}$, which mainly depends on the solar radiation and from the PV panels depreciation. The bigger is $\Delta T_{M}$, the higher is level of the depreciation of some subcells.

Minimum: $8,3^{\circ} \mathrm{C}$ Maximum: $13,6^{\circ} \mathrm{C}$ Average: $9,2^{\circ} \mathrm{C}$

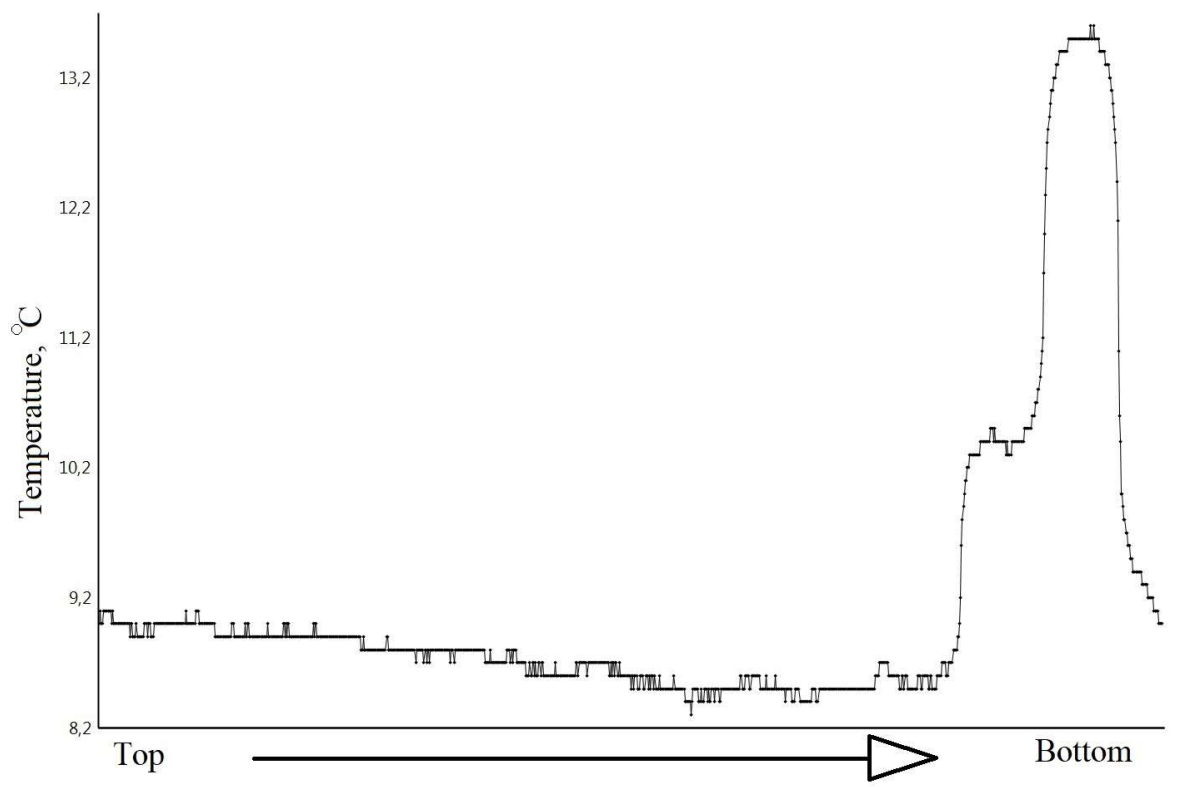

Fig. 9. Histogram of the tested PV panel № 2 .

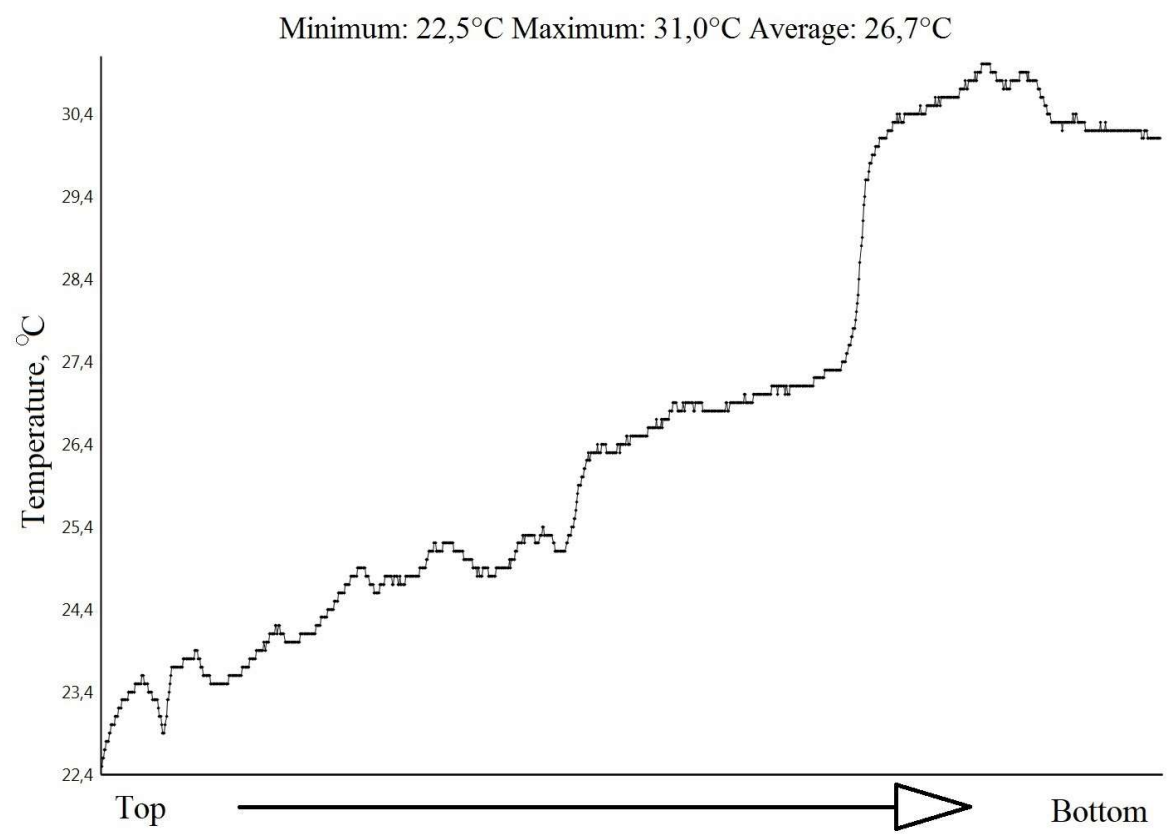

Fig. 10. Histogram of the tested PV panel № 8 . 
Minimum: $5,8^{\circ} \mathrm{C}$ Maximum: $13,7^{\circ} \mathrm{C}$ Average: $9,2^{\circ} \mathrm{C}$

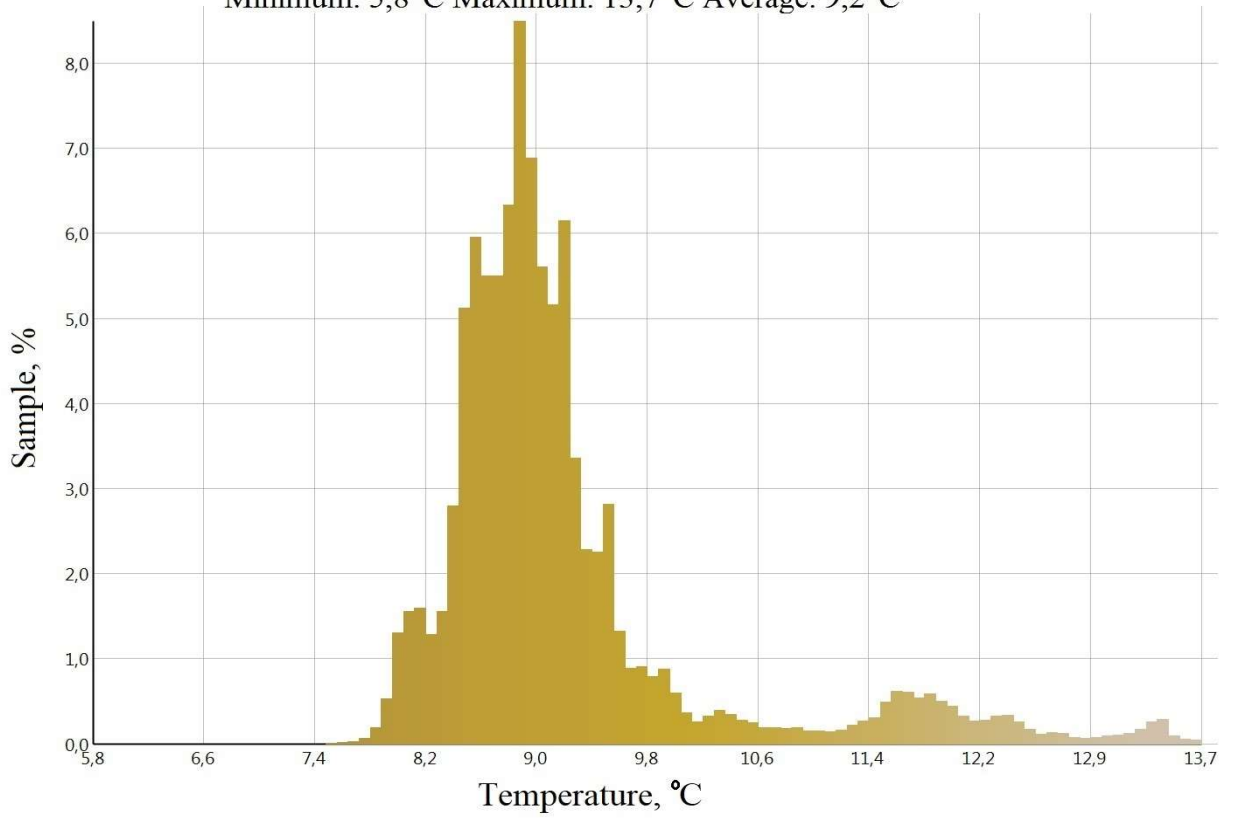

Fig. 11. Vertical thermal curve (VTC) of the tested PV panel № 2.

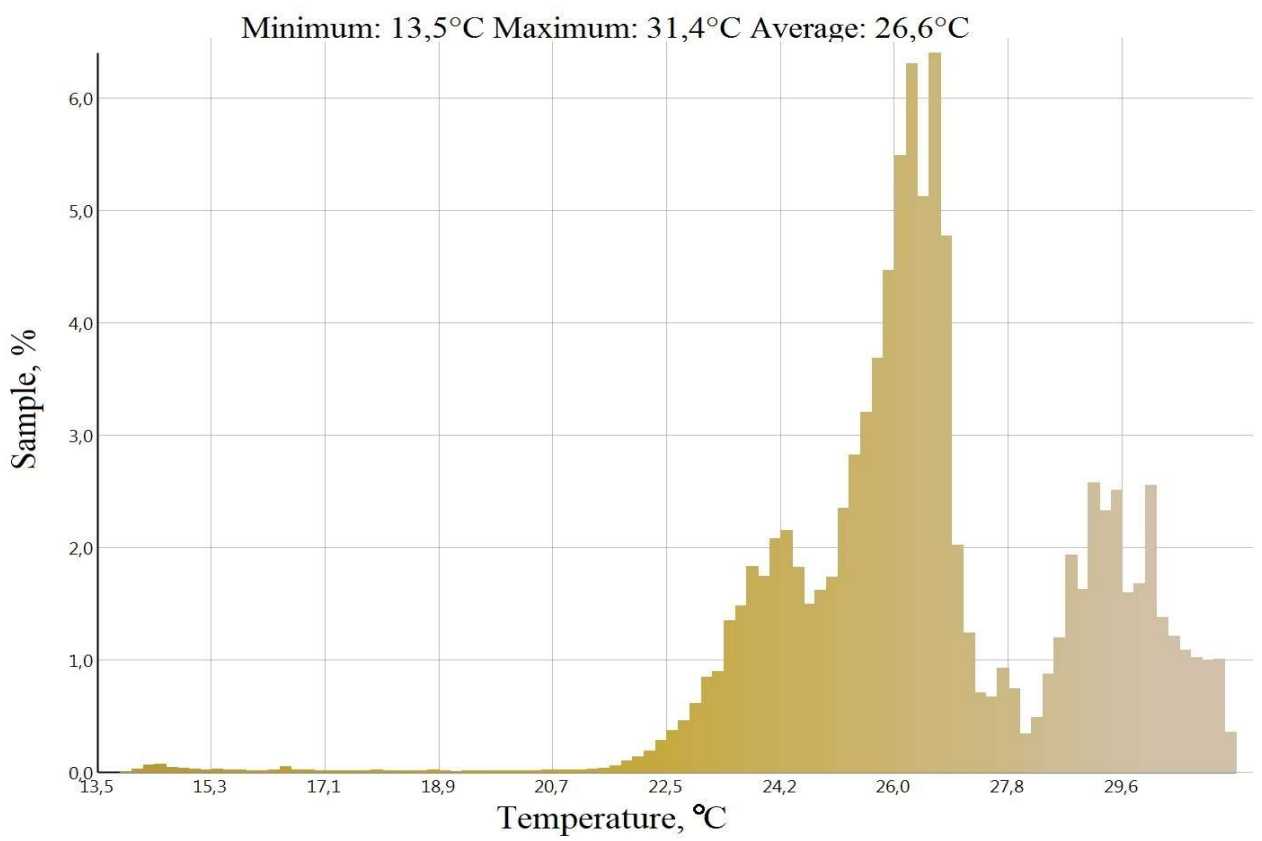

Fig. 12. Vertical thermal curve (VTC) of the tested PV panel № 8.

\section{Conclusions}

The combined approach used for monitoring of the PV power plant in real field conditions gave interesting results about the efficiency, operating mode and temperature distribution over the PV panels. The main conclusions derived from this study are: 
- The calculated solar radiation using Global base data have a large deviation from measured levels. The changing local meteorological conditions impact the measurements and reduce the solar radiation in a big scale.

- Maximum level of the measured solar radiation on the tilted PV panels' surface is 503,6 $\mathrm{W} / \mathrm{m}^{2}$.

- On this time season and after a 5 year of period of exploitation, the efficiency of the PV panels is between $11,3 \%$ and $12,8 \%$.

- Obtained values for the Fill factor $(F F)$ for the tested PV models are within the interval 0,75 $\div 0,76$.

- The maximum temperature differences over the panels' surface received via thermography is within the interval $2^{\circ} \mathrm{C} \div 10,5^{\circ} \mathrm{C}$.

- The most of the tested panels show the higher level of the temperature on the bottom located subcells - in the lower levels of the construction. Furthermore, some separate cells of the panels № 5, № 6, № 7 and № 8, shows indications for overheating.

- Using histogram of the thermographic images, can be located the risky area on the panel's surface. Deviations on the right side of the main distribution show area with higher risk of damage. By the histogram using further calculations the ratio between the risky and whole area of the PV panel can be obtained.

- The vertical thermal curve (VTC) could be useful tool for assessing reliability of the whole string into the tested PV panel.

The used combined approach and the received results can be used for monitoring and estimation functionality and depreciation of each module of a PV power plant at the subcell level in short time. It is clear, that for more relevant data the frequently measurements during the appropriate time periods have to be done, but this study reveals a comparatively fast method for assessment the current state of each PV plant and the received data are limited in a short-time period respectively.

\section{References}

1. T. Markvart, L. Castaner, Practical Handbook of Photovoltaics: Fundamentals \& Aplications, Elsevier, (2003)

2. R. Messenger, J. Ventre, Photovoltaic Systems Engineering, CRC Press, (2004)

3. M. A. Green, Silicon Solar Cells: Advanced Principles \& Practice, University of New South Wales, (1995)

4. https://www.enfsolar.com/pv/inverter-datasheet/5129

5. https://www.enfsolar.com/pv/panel-datasheet/crystalline/2503

6. P. Kadar, A, Varga, Intelligent Systems and Informatics, IEEE, 549-552, (Subotica 2012)

7. C. A. Gueymard, D. Myers, K. Emery, Solar Energy, 73, 443-467, (2002)

8. F. Kasten, A. T.Young, Applied Optics, 28, 4735-4738, (1989)

9. A. B. Meinel, M.P. Meinel, Applied Solar Energy, Addison Wesley, (1976)

10. E. G. Laue, Solar Energy, 13, 43 - 50, IN1-IN4, 51-57, (1970)

11. https://wui.cmsaf.eu/safira/action/viewProduktDetails?eid=21839\&fid=19

12. https://www.nrel.gov/grid/solar-resource/spectra-astm-e490.html

13. https://re.jrc.ec.europa.eu/pvg_tools/en/tools.html\#PVP

14. R. E. Bird, C. Riordan, J. Climate and Appl. Met., 25, (1986)

15. Z. Hameiri, K. McIntosh, Photovoltaic Specialists Conf., IEEE, 1416-1412, (2013)

16. M. A. Green, Solid-State Electronics, 24, 788 - 789, (1981)

17. M. Leilaeioun, Z. C. Holman, J. Appl. Physics 120, 123111, (2016) 